\title{
The Storybook Account of Orthodontics and Anthropology
}

\author{
J. Philippe
}

\section{SUMMARY}

For a long time, orthodontics has developed without ever showing the slightest interest in anthropology. However, during the first half of the 20th century, we realized the need to link craniometry and anthropology. After this, orthodontics adopted cephalometric analysis, a new procedure based more upon a diagnostic and therapeutic approach, rather than a simple academic approach, thus separating it from anthropology.

\section{KEYWORDS}

Cephalometric Analysis, Anthropology, Craniometry, History of Orthodontics

\section{INTRODUCTION}

The relationship between anthropology and orthodontics could easily be described as romantic. Orthodontics first ignored anthropology, then fell madly in love with it, and finally turned away. The two disciplines behave like humans.

\section{ORTHODONTICS IGNORES ANTHROPOLOGY}

For a century after Fauchard (1728), practitioners fixed each tooth individually without worrying about the arch as a whole. Starting in 1830, they began to consider the shape of the arches, and expanded their understanding by thinking that functional dysfunctions could be related to the arches. At the end of the 19th century, two Americans, Kingsley and Case, found ways to modify the anterior and posterior relationships between arches. All these advances took place without the orthodontists even considering the bone bases or skulls and without invoking anthropology (with the exception of J. Hunter).

At the beginning of the 20th century, orthodontic mechanics became more diversified and, above all, advanced. It 
became possible to move teeth or groups of teeth in a significant way. Moreover, in the absence of the control that the technique of superposition of the layers of teleradiographs would subsequently bring, the practitioners imagined that the displacements they were making were even

\section{USES OF ANTHROPOLOGY}

Concerned about the extent of the power they imagined they had, the practitioners sought a guide.

They found a solid discipline in anthropology, which was thriving in the early 20th century.

The orthodontists thought that, if anthropology is the science of man, then orthodontics, which modifies the face, may well be a small part of anthropology. Orthodontics is relatively small in that it is limited to the face, but important because of the functions that it concerns and by the role that facial appearance has, which is linked to our social identity. In this sense, any orthodontic research and any orthodontic procedure could be considered research or an act of anthropology.

In 1906, A. Pont ${ }^{3}$ presented his famous tooth/arch index established purely from an anthropological viewpoint, but whose simplification, in 1909, was so appealing to orthodontists that it became more than just a diagnostic tool, and was rather used in an abusive manner as the very basis of orthodontic treatment until approximately 1960. more complex than they actually were. Today we question anyone who says "to advance the upper teeth by $14 \mathrm{~mm}$ in rectilinear translation." At that time, it was not surprising that it was believed that the bone base would undergo adaptive growth of the bone base (Angle theory).

When studying prognathism, H. Villain ${ }^{5}$ in 1908, refers to the work of Topinard and Broca. He speaks of craniology and proclaims himself an anthropologist.

After a silent period because of the war, the 1920s saw orthodontics embrace anthropology.

In 1921 S. Dreyfus ${ }^{1}$ wondered, "When faced with a Class-Il case, for example, are we in the presence of a prognathism, a retrogeny, or a combination of the two? We know nothing about it, but we should so that we can treat properly... What we lack, then, is a fixed, immutable base, independent of personal appreciation and invariable according to individuals, which allows us to judge." Dreyfus found the answer by establishing three orthogonal planes, including the Frankfurt plane, which allowed him to appreciate the position of all the anatomical elements in the three spatial dimensions.

In 1922, A. Siffre ${ }^{4}$ studied the dental arch, both temporary and permanent. A. Siffre was an astonishing man was! He was a dental technician (we used to call him a dentist mechanic). He studied at night and graduated as an 
oral surgeon, he was still studying and became a medical doctor, but he did not finish his studies and yet he found himself director of the "École Odontotechnique" (Orthodontics School), vice-president of the Société Française d'Orthopédie Dento Faciale (S.F.O.D.F.) (French Society of Dental and Facial Orthopedics) and President of the Paris Anthropological Society! He embodies the link between anthropology and orthodontics, because in 1905 he created the first orthodontic service in Garancière.

In 1922, G. Izard ${ }^{2}$ had orthodontists adopt, as a blueprint for the orientation of the head, the Frankfurt blueprint chosen by anthropologists as early as 1882, thus establishing a certain unity between the two disciplines.

Many other names deserve to be mentioned, but more than just names, the fact that all the authors of this era tried to give an anthropological support to their orthodontic proposals show the degree that anthropology influenced orthodontics.

The orthodontists' passion for anthropology led to the development of an incredible number of instruments that allowed the principles of cephalometry to be applied on living patients. As a result, we now have: the sagitometer, occlusometer, goniometer, profilometer, circometer, cephalometer, and backstage cephalometer, keyridgometer, atresiometer, prosopometer, mesiometer, maxilator, cephaloscope, and diagnosticope (Figs. 1 and 2). L. de Coster counted a hundred devices of this kind. They testify to the enthusiasm of practitioners for anthropology.

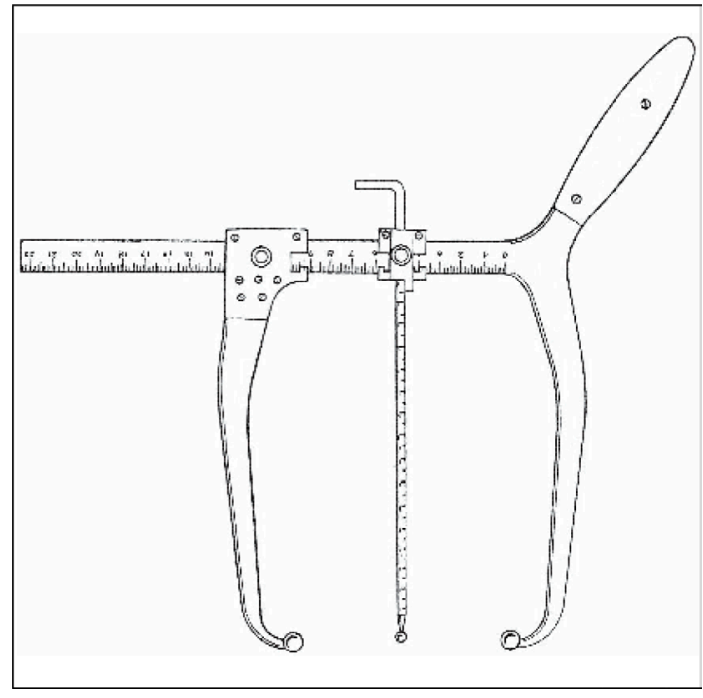

Figure 1

The Slide Cephalometer, "To raise the value of the facial axes usually considered in dental and facial orthodontics" (Pr. Maronneau).

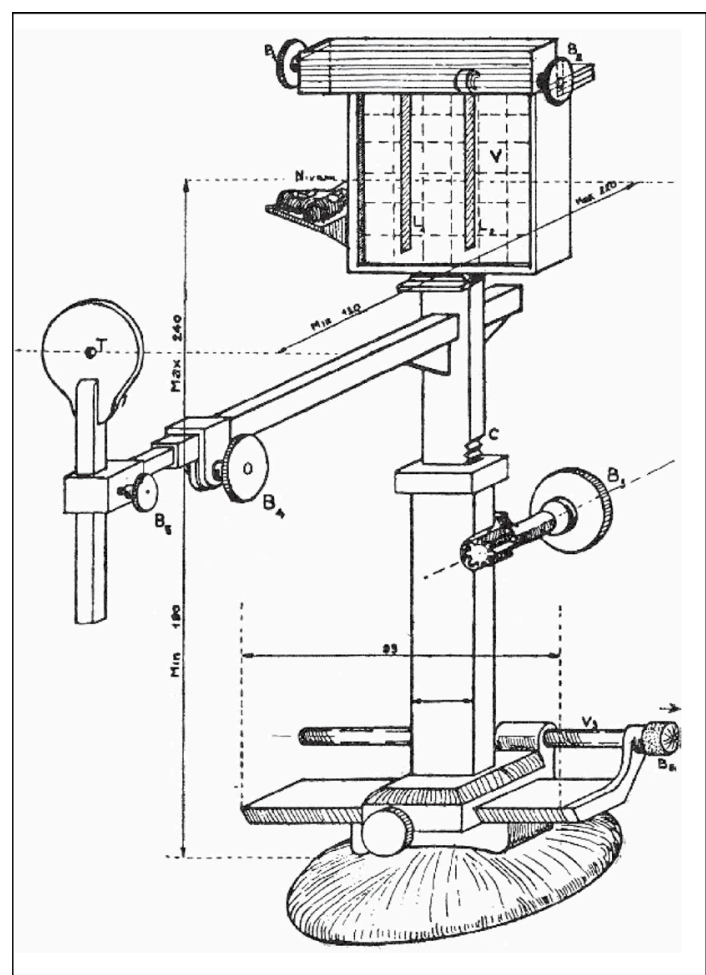

Figure 2

Cephalometer "To diagnose maxillofacial and facial anomalies and control their treatment."

(Dr. J. Merle-Béral). 


\section{ANTHROPOLOGY AND TELERADIOGRAPHY}

In the 1930s, cephalometry was based on dry skull measurements. The living studies were made imprecise by the constantly varying thickness of the surrounding tissues. This discipline was upset by the appearance of a new examination procedure: profile teleradiography of the head, which allowed measurements to be taken on the living. Although the projection of the oblique structures on a sagittal plane decreased their dimensions and although the transverse dimension of the face had disappeared, the teleradiograph allowed practitioners to see almost inaccessible structures and proved to be an extremely valuable instrument.

Classical cephalometry work, but carried out using teleradiography, began to develop in Europe (Korkhauss, De Coster, etc.). Many of them turned to studying the growth and development of the skull that could not have been carried out on dry skulls, but this work was quickly stopped by war. Others continued successfully in the European Union (Broadbent, Brodie, Hellman).

After the war, in the 1950s, some followers continued to develop cephalometry in an anthropological spirit, such as Autissier (1949), Björk (1950), Crambes, (1957) De Coster (1952), Fernex (1932), Gudin (1952), Muzj (1948), and Rousseau (1952).

Moreover, the talents of a certain scientist, R. Jerome, created a new branch of craniometry and the study of facial development by considering the orientation of the equilibrium organs, such as the semicircular canals of the inner ear. He recruited orthodontists who had a taste for research and, with their help, published a series of works of high scientific value from 1968 to 1995.

\section{CEPHALOMETRIC ANALYSIS}

During and after the war, American Orthodontists carried out the first research into cephalometric work on teleradiography, and developed a new method of interpreting measurements: Cephalometric analysis. It evaluates the position of the anatomical elements that interest the orthodontists in relation to the skull base or the Frankfurt plane.

Most practitioners abandoned classic cephalometry, and its orthogonal planes, for the new method better suited to their practice. They relied on the proposed figures to identify treatment targets, which were referred to as "standards".

With the analysis appeared the techniques of layer superposition which allow to objectify the results of the treatments. Their first effect was to bring practitioners back to more modesty in the appreciation of the results obtained by the treatment. 


\section{THE RIFT}

The development of cephalometric analysis and its intensive use revealed a rift between anthropology and orthodontics. In reality, this rift emerged as soon as the orthodontists started using the orthogonal planes to guide their treatments, but it was then veiled by the inaccurate measurements they obtained.

Anthropology seeks to know what it is. Orthodontics seeks to change what it is.

The anthropologist wants to advance science. The orthodontist wants to help their patient. For doing so, the orthodontist must make nonscientific, and therefore questionable, judgments of value.

When anthropology measures the size of an anatomical structure or the relationship between two structures, it does not make judgments. When faced with a group of subjects, it calculates the average of an element and, possibly, compares it to that of another group, without supporting one or criticizing the other. Orthodontics measures the relationship between two structures, finds its difference with the average and believes that this difference is a disadvantage for the subject. Then, it assigns this difference to one of the two measured structures (the one of interest) and tries to move it until the measurement has recovered the average value, which claims to be ideal for the subject.

The intellectual pathways are radically different.

\section{CONCLUSIONS}

Orthodontics has contributed to the field of anthropology. We can mention their mastery of teleradiography, which allowed Broadbent, Brodie, and Hellman to study facial development. But above all, we must emphasize the value of the work of $\mathrm{R}$. Jerome which has never been equaled.

Orthodontists first ignored anthropology. Then they relied on this discipline to support their diagnoses. Today the orthodontists have abandoned anthropology and use cephalometric analysis which they consider to be better suited to their practice. The scientific ideal of anthropology cannot be equated with the therapeutic will of orthodontics. Anthropologists focus on the progress of science; the orthodontists focus on the well-being of their patients.

It can be assumed that in the future, orthodontics will focus less on forms and more on functions. In this hypothesis, it would become more medical. These changes would not lead to a closer relationship between the two disciplines. Admittedly, both focus on man, but anthropology is a science and orthodontics is an art.

Conflict of interest: The author declares that they have no conflict of interest. 


\section{BIBLIOGRAPHY}

1. Dreyfus S. Le diagnostic en orthodontie. Orthod Fr 1922;1:35-60.

2. Izard G. Choix d'un plan horizontal d'orientation en Orthodontie. Orthod Fr 1922;1:85-96.

3. Pont A. Contribution à l'étude du traitement de l'atrésie du maxillaire. Association Française pour l'Avancement des Sciences, 1906.

4. Siffre A. Étude de l'arc dentaire chez l'homme. Identité de l'arc temporaire et permanent. L'Orthod Fr 1922;1:111-120.

5. Villain $\mathrm{H}$. De l'emploi des forces inter-maxillaires en orthodontie pour la correction du prognathisme. Le Laboratoire, 16 fév. 1908. 